\section{A voice for dental providers}

The Association of Dental Groups (ADG) promotes high quality dentistry throughout its membership of dental providers. It also utilises its collective knowledge and expertise to drive change and support government decisions for the ultimate benefit of patients and all dental practices in the UK.

It has been endorsed by Neil Lloyd, Chief Executive Officer of dental corporate Dental Partners, who said: 'Dental Partners joined the ADG to have a greater voice as the profession goes

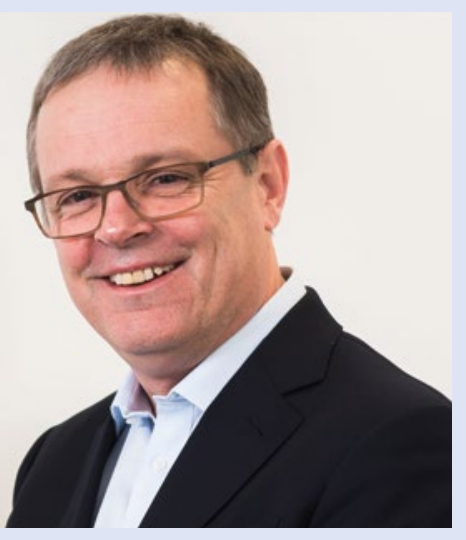

through a period of intense change - for example with the new potential contract and Brexit.

'The ADG meetings have been a great source of information and advice on a wide range of topics affecting the dental profession and corporate dentistry in particular'.

More information about the ADG is available by visiting www.dentalgroups.co.uk.

\section{High-capacity rapid heat tabletop steriliser now available}

After a period of lengthy development, CPAC Equipment, Inc. is pleased to announce the February 2019 rollout of their new RapidHeat Pro11 HighCapacity Tabletop Sterilizer.

With more than $700 \%$ (seven times) more capacity than its COX RapidHeat predecessor, the Pro11 has the industry's fastest 'complete' cycle turnaround.

Unlike steam sterilisation, there is no FDA required drying cycle that can be short-cut to speed up the process. The Pro11's complete full cycle is 12 minutes unwrapped or 18 minutes wrapped.

The time/temperature profile established for each cycle has been documented to exceed a $12 \log 10$ bacterial spore kill. This documentation is based on a steriliser capacity of four instrument trays, each containing a load of more than 1.75 lbs. representing a total steriliser capacity of approximately 140 medical or dental instruments.

Since no water or steam is used, independent tests have confirmed there is less maintenance expense with each Pro11 cycle consuming $85 \%$ less energy than comparable steam sterilisers.

These tests have also confirmed that the RapidHeat waterless sterilisation environment does not contribute to the instrument corrosion and shortened instrument life that has been proven to be characteristic of steam sterilisation.

For more information email dbaker@ cpac.com.

\section{Bring a new dimension to your practice}

Dental professionals wanting their practice to take advantage of the $3 \mathrm{D}$ printing revolution, but have a lack of space, expertise or finances to add the machinery to their facilities are being offered the perfect solution.

Sparkle Dental Labs is a full service laboratory offering reasonable prices and an efficient turn around on a wide range of products, including 3D printed solutions.

It claims to be the very first dental lab in the UK to use both the Renishaw AM250 Laser Sintering Machine and DryLyte Chrome Polishing System on the same premises.

More information is available by visiting www.sparkledentallabs.com, calling 0800 1386255 or emailing customerservice@ sparkledentallabs.com.

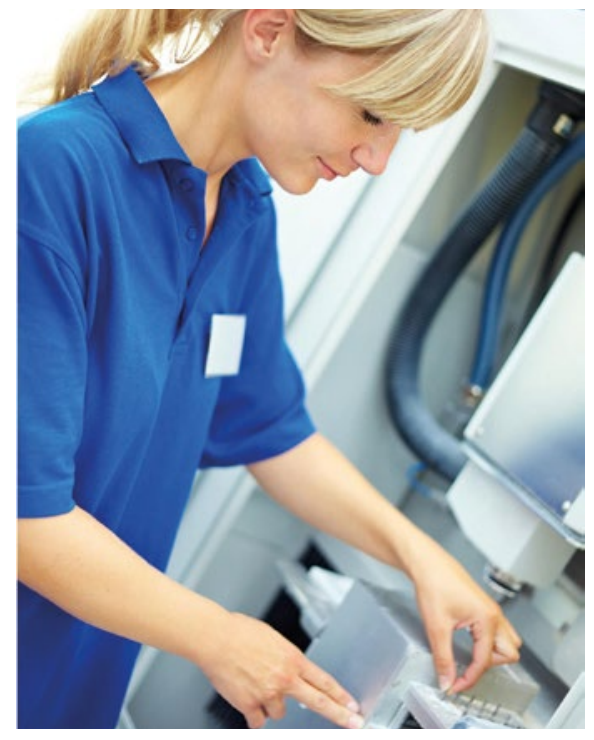

\section{Say cheerio to perio}

Assessing the true extent of periodontitis can be difficult, so why not use PROPACS from PRO Diagnostics UK?

A secure cloud-based storage system, PROPACS can also be used to assess and monitor periodontitis. You simply send radiographs to their team of specialist radiologists and they will create a PerioGuide report.

This report uses an easy to understand colour coded system to assess the severity of periodontitis and also give information

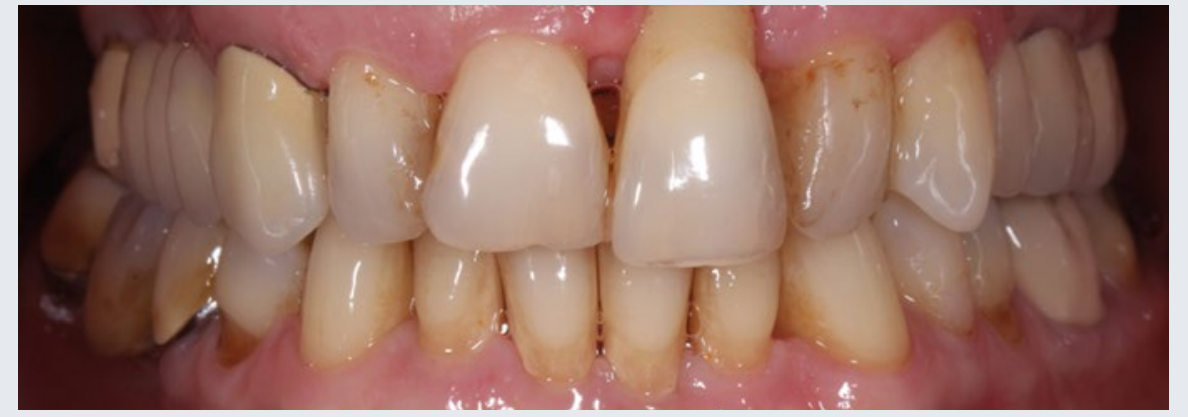

such as the amount of bone loss at each tooth site - everything needed to accurately classify the severity of periodontitis and treat it.
More information can be seen by visiting www.prodiagnostics.co.uk or emailingsales@prodiagnostics.co.uk. 